\title{
Avatar, Dark Green Religion, and the Technological Construction of Nature
}

\author{
CHRIS KLASSEN
}

WILFRID LAURIER UNIVERSITY

James Cameron's Avatar (2009) exploded onto screens with a vision of splendour aided by a highly advanced system of computer generated imagery (CGI) and 3D technology. Many viewers were awed by the world and worldview they encountered on Pandora, the main locus of action in the film. A significant element of appeal was the spiritual interaction of the indigenous peoples of Pandora, the Na'vi, with the rest of their 'natural' world. Bron Taylor and Adrian Ivakhiv point out that Avatar's depiction of Na'vi religion 'ventures deeply into the terrain described variously by such terms as animism, pantheism, panentheism, paganism, ecospirituality, and "dark green religion"'. ${ }^{1}$ Dark green religion is a concept developed by Taylor to make sense of a growing popularity of thinking about the environment in spiritual terms. Many fans have taken Avatar to be a story about a desirable spirituality embedded in the 'natural' world. For some, Avatar becomes a motivation to act differently in their everyday lives, particularly in response to environmental issues. Others suffer what Matthew Holtmeier calls Post-Pandoran Depression whereby they grieve the inability to live in the Avatar world. ${ }^{2}$ 
In attempting to take seriously the way Avatar represents this kind of ecospirituality, or dark green religion, I suggest that more than simply the narrative must be analysed. I argue that one reason for this Post-Pandoran Depression is that Avatar does not actually represent a 'natural world' as such, but rather it refracts nature, providing an optical illusion of a spiritually embedded nature. This fantasy is hyperreal and thus leads viewers to an engagement with a nature that is both 'unnatural' (that is, constructed by human technology) and 'better than' or 'more than' the environment we currently inhabit. As an entertaining fantasy film, there is nothing inherently wrong with a construction of a fantastical 'natural' world. But as a representation of dark green religion, it must ultimately fail as it can only promote a kinship to a fictional 'nature'. This failure is caused by a confusion of the referential index presented in this film-leading to an optical illusion of nature and ultimately a dark green religion based on fantasy.

This representation of 'nature' found in Avatar begs a number of questions. The first is concerned with the mediation of 'nature' through technology. To what extent do digital effects and 3D technologies alter the way viewers can access the nature that is represented in the film? The second question is related: to what extent is Pandoran nature, represented through special effects technology, a rival to the 'real' world (Earth)? To put it another way, does Avatar give us a new and improved, through human technology, natural world? If so, how does this hyperreal nature reshape dark green religion into an optical illusion? To begin answering these questions I will first explain the concept of dark green religion and show how Avatar fits that trope. I then explore the implications of the technologies of CGI and stereoscopic 3D, followed by a discussion of the kind of nature constructed with these technologies.

\section{-DARK GREEN RELIGION}

Bron Taylor makes a distinction between green religion and dark green religion. Green religion is most appropriately used, he claims, for religious organisations or traditions that are trying to incorporate environmentally sustainable practices and worldviews as reinterpretations of traditional concepts. Dark green religion differs in its fundamental inclusion of the natural world within the category of the sacred: 
This value system is generally (1) based on a felt kinship with the rest of life, often derived from a Darwinian understanding that all forms of life have evolved from a common ancestor and are therefore related; (2) accompanied by feelings of humility and a corresponding critique of human moral superiority, often inspired or reinforced by a science-based cosmology that reveals how tiny human beings are in the universe; and (3) reinforced by metaphysics of interconnection and the idea of interdependence (mutual influence and reciprocal dependence) found in the sciences, especially in ecology and physics. ${ }^{3}$

The concept of dark green religion, then, modifies a generalised term of nature religion-a term that scholars such as Catherine Albanese have been able to use for a wide variety of religious movements oriented towards nature. Dark green religion, according to Taylor, is not only oriented towards nature, it preferences nature. ${ }^{4}$ Whereas Albanese allows for both a drive towards mastery and harmony with nature in her formulation of nature religion, Taylor's dark green religion is fundamentally about harmony.

Pointing to the explanatory potential in his formulation, Taylor explores a wide variety of examples that he sees as exemplifying dark green religion. From transcendentalism to surfing culture, from Disney's Animal Kingdom to Jane Goodall, Taylor remarks on a growing popularity of nature spirituality that can be seen as dark green. The popularity of nature-based religion and/or spirituality has been noted by scholars of both religion and popular culture. In religious studies much of the work on nature-based religion has focused on contemporary paganism or feminist goddess worship as growing new religious movements. ${ }^{5}$ In these traditions deity, in either the pagan polytheistic forms or the monotheistic Goddess, is imminent within the physical realm and ritual revolves around seasonal cycles and natural processes, particularly of the female reproductive body. Many contemporary pagans and goddess worshippers (and at times these categories are conflated) also would identify strongly with ecofeminist concerns. Ecofeminism posits a philosophical, historical, and psychological connection between the treatment of the natural world and the treatment of women. ${ }^{6}$ Conceptualising the natural world as goddess(es) or the feminine divine, thus, becomes a part of contemporary pagans' and feminist goddess worshippers' environmental activism. As such, these groups 
epitomise Taylor's category of dark green religion: they see humans as part of the natural world, which is characterised by a metaphysics of interdependence and interconnection.

Dark green religion, or a concern with nature spirituality, is not confined to these specific religious groups. Scholars interested more specifically in popular culture media have also noted growing interest in themes of a spiritual connection to the natural world. This connection is often tied to portrayals of indigenous peoples, who are often portrayed through the trope of the ecological 'noble savage', whereby Indigenous peoples are perceived to have special wisdom about the natural world but only insofar as they remain tied to a modern Western perception of pre-contact spirituality and cultural practice. ${ }^{7}$ Taylor himself appeals to popular cultural versions of dark green religion in his discussion of the Disney films, Bambi (1942), The Lion King (1994) and Pocahontas (1995), the last also employing the ecological noble savage trope. Each of these films, Taylor suggests, bring an experience of sublime nature to viewing audiences. As a happy coincidence, just around the time that Taylor's book, Dark Green Religion, was published, James Cameron's blockbuster film Avatar was released. A film with a clear narrative of kinship among multiple species on the moon called Pandora seems on many levels to reflect the dark green religion Taylor sees all around us.

In Avatar we have the story of a conflict between human colonisers and the indigenous peoples of Pandora, the Na'vi. The Na'vi live in close relationship with the natural world around them, recognising the symbiotic connection running throughout the moon. They deify this interconnection in the mother goddess, Eywa. The humans, on the other hand, are capitalists who measure their superiority through technology but are positioned within the narrative as spiritually disconnected from their natural environment. The story revolves around the experiences of the now paraplegic marine, Jake Sully, who interacts with the Na'vi by interfacing with an avatar-a body made up of human and Na'vi DNA that looks Na'vi. As Sully learns the Na'vi ways, he becomes increasingly enamoured with their worldview and ultimately chooses to help them resist the capitalist takeover. In the end, Sully chooses to discard his damaged human body and merge his mind permanently with his avatar body to become Na'vi. 
If dark green religion is characterised as incorporating a sense of kinship with the rest of the natural world, a feeling of humility and criticism of human hubris and a metaphysical construction of interdependence of all life, the worldview of the Na'vi on Pandora would seem to fit nicely into Taylor's theories. The Na'vi understand themselves to be part of an interdependent relationship with all Pandoran life. They honour the life given for their own sustenance and give themselves back to the whole planet, deified as Eywa, at their own deaths. Britt Istoft has argued: 'In many respects Avatar can be said to correspond to ideas developed in twentieth-century Paganism. ${ }^{8}$ Istoft takes this analysis beyond the film to fan responses and suggests that the 'potential of Avatar fandom for the production of nature religion is clear, as well as its ability to provide fans with meaning and an ethical orientation to the world'. ${ }^{9}$ Holtmeier complicates this audience reception, however, by noting that while some fans have certainly used Avatar as a motivation for environmental and social activism, others seem to get lost in what he calls Post-Pandoran Depression. Post-Pandoran Depression involves 'a recursive relationship with the film that leads fans to return to the fictional world of Pandora, rather than seeking change in their lived realities'. ${ }^{10}$ Key to understanding this reaction, as well as the way Avatar fits within the dark green religion trope, is to explore the implications of the technological construction of nature found in the film. Though all representations of nature are necessarily constructed, in this instance the lack of referential index is significant. We are given a refraction that bends the image into an optical illusion. I suggest that the implications of refraction require extra work on the part of the viewer. A simple engagement with the spectacle of the imagery cannot lead to any real world engagement with nature as the imagery of Avatar has no referential index. Those who choose to apply dark green religious messages gleaned from Avatar allegorically, must work against the technological sublime presented in the film to orient their engagement with dark green religion to environmental issues outside of the film's diegesis. That a number of fans have submerged into a PostPandoran Depression is evidence of the conflation of the film's textual diegesis with extra-textual environmental concerns. 
Taylor suggests that recent animated Disney films such as The Lion King or Pocahontas bring the experience of the sublime in nature to the big screen. However, if, as Greg Tuck describes it, the sublime is characterised by 'the awe inspired by grand natural phenomena such as mountain ranges and powerful storms' we must ask how the use of technologies like animation or stereoscopic 3D mediate the experiences of the sublime. ${ }^{11}$ This questioning follows Stephen Muecke's urging to pay attention to the 'contingencies we bracket out, they could be the necessary conditions for the conducting of an experiment: who is funding it, and why? Is the corporation demanding quick results? Whose career is on the line? ${ }^{\prime 2}$ I would add, what technology is used? And, how does it affect perception? Can one experience the sublime if the 'nature' being experienced is human-made? Or is it merely spectacle?

David E. Nye argues for the existence of an American technological sublime that moves the sublime experience out of the natural world and into an engagement with increasingly advanced technological constructions, from the early railroad to the Golden Gate Bridge to Las Vegas. If Nye is right, technology does not eliminate the experience of the sublime. It does, however, change the conception of and appeal to the sublime. This change becomes more and more relevant as the technological sublime becomes consumer driven. Nye writes of what he calls the consumer's sublime:

Unlike the Ford assembly line or Hoover Dam, Disneyland and Las Vegas have no use value. Their representations of sublimity and special effects are created solely for entertainment. Their epiphanies have no referents; they reveal not the existence of God, not the power of nature, not the majesty of human reason, but the titillation of representation itself. The genuine ceases to have any special status; the faked, the artificial, and the copy are the stock-in-trade. ${ }^{13}$

What Nye describes above is the transformation of the sublime into the spectacle.

In the same vein, Tuck suggests that CGI is spectacle in that 'we know the senses are being played with, and so however fabulous the images in front of us, they never exceed understanding. We might not know exactly how the spectacle has been achieved, but in principle we know that we could. ${ }^{14}$ As we watch Avatar, in knowing the natural world of Pandora is computer generated, our ability to engage 
with it as sublime is limited. We are, as Tim Blackmore suggests, faced with an 'inherent ideology in high-end digital special effects.' ${ }^{15}$ Even as we marvel at the beauty of the Hallelujah Mountains-a range of rock formations on Pandora that defy gravity and float-we also 'are invited to marvel at a complex technical achievement, and challenged to locate discrepancies in the illusion'. ${ }^{16}$ In this sense, the sublime we engage with is technological spectacle with limited use value. Avatar is not simply about the particular narrative of indigenous spirituality tied to the natural world. It is a special effects film that uses CGI, an effect in which the object seen only appears to be an index of any referent. Its physical presence 'is merely a quantity of data in a microchip'. ${ }^{17}$ Or, as James Cameron himself said, his main female protagonist, Neytiri, 'exists only as a big string of ones and zeroes'. ${ }^{18}$

Not only do we view a CGI constructed nature, Avatar was designed to introduce new 3D technology (though a 2D version is also available). ${ }^{19}$ Joshua Clover suggests that this need for visual augmentation falls in line with the larger corpus of Cameron's work, which Clover says, 'is organized by a single idea: the necessity of the augmented human body in the struggle against inhuman beings'. ${ }^{20}$ In Avatar we get this augmentation in the narrative, whereby Sully is augmented with an avatar body, as well as in the experience of viewing. To experience the true technological genius of Cameron's vision, we must wear 3D glasses. Avatar becomes, then, a new frontier in movie making. It is 'a new space for James Cameron to assert dominion over-armed only with a quarter-billion dollars and all the technological augmentation it can buy'. ${ }^{21}$

If Avatar fits in the theme of augmentation, we must think about the implications of these augmentations. What does it mean to 'see' in stereoscopic 3D? Cameron claims that 3D 'gives you more of a sense of participation, involvement, and immersion. You feel like you're bearing witness, and that makes the journey feel more real. ${ }^{22}$ Cameron's opinion notwithstanding, technologists and scholars (and anyone who has actually used 3D glasses, I would presume) agree that the way we see with 3D glasses is not the way we see the real world around us. ${ }^{23}$ The mediation of a screen alters the way the eye perceives the image. In simple physical terms, our vergence distance and our focus distance are generally the same, with some variation due to degrees of myopia. Vergence is the way our eyes rotate around a vertical axis to converge on a given object in the distance. In stereoscopic 3D our 
eyes are asked to focus on a fixed distance (the screen) while also negotiating the simulated vergence distances. As Kirk Kroeker points out, this disparity 'causes a physiological disconnect that can lead to headaches and even nausea'. ${ }^{24}$ Our bodies must compensate for the ocular gymnastics we are required to participate in. A CGI nature viewed in stereoscopic 3D amplifies human control over the imagery of nature while pushing our bodies to act in ways to which they are unaccustomed. That some viewers' bodies reject this requirement and even become physically ill suggests that Cameron's hope that 3D technology will make the 'journey feel more real' is possibly limited.

This marvellous technological construction is represented by Cameron and popular appreciators as a product of human ingenuity and progress. Another perspective could be drawn from John A. Livingston's Rogue Primate where he explores what he calls the human self-domestication for the benefit of 'technological abstraction'. ${ }^{25}$ For Livingston, the goal of human domestication is 'the humanisation of the planet', a process that is necessary and is 'justified-indeed, sanctifiedfirmly and unequivocally for the advancement of the human enterprise'. ${ }^{26}$ In constructing a representation of nature via CGI and 3D technology, Cameron is domesticating nature-making it solely a product of human construction to follow human ideals and techniques for the purposes of highlighting human technological prowess and power over our surroundings.

\section{-THE HYPERREAL}

Beyond the implications of experiencing a constructed 'nature' through the lens of CGI and 3D, we can also question the kind of nature represented. Just as Clover suggests that the use of 3D technology, which requires augmentation of our eyes with 3D glasses, fits into Cameron's milieu of augmentation, so too the natural world of Pandora is an augmented nature. There are trees two to three times the height of the redwoods of the Pacific Northwest. Many Pandoran plants and animals exhibit bioluminescence. The direhorses that the Na'vi ride are a third larger than draft horses and have six legs. The Na'vi are bigger and stronger than humans. There is a quantifiable physical network of energies between all life. ${ }^{27}$ Pandora is 'more than' the earth; it is a hyperreal nature. 
Shelly R. Scott analyses the construction of nature in Disney's Animal Kingdom (DAK), a site to which Taylor attributes the category of dark green religion. Scott's critique, though, is cutting and also relevant to the constructed nature of Cameron's Avatar. ${ }^{28}$ Scott sees DAK as attempting to improve upon, rather than conserve or reflect, nature. This is due not only to the negative ecological practices of the company-and the tourists each spending hundreds of dollars a day to have a 'nature' adventure. Scott is most concerned with the construction of a hyperrealism, drawing on Umberto Eco. Eco examines the American fascination with reproductions and authenticity in museums, amusement parks and zoos, where if something looks real it must be real, even if there is no referential index to authenticate it. An example he gives is the occurrence of multiple wax versions of Leonardo da Vinci's Last Supper displayed next to an 'original' which itself is neither original nor authentic likeness to the original. Viewers are supposed to prefer the wax version and, says Eco, in that preference, to have 'the most extraordinary spiritual experience of your life'. ${ }^{29}$ He calls this American fascination with reproductions 'the industry of the Absolute Fake' and argues that it is not confined to the reproduction and/or improvement of works of art, but extends to the relationship with the natural world as well. ${ }^{30}$

In discussing Disneyland, a model of this Absolute Fake, Eco argues, 'Disneyland tells us that technology can give us more reality than nature can'. ${ }^{31}$ Scott similarly draws particular attention to the central symbol of DAK-the Tree of Life-which 'is huge, phony, and inaccessible. For this visitor, what it most emphatically is not is a sign of life; it is indeed the epitome of the park, as much else that seems real from a distance is hyperreal upon closer examination. ${ }^{32}$ The augmented nature of Pandora also seems hyperreal-a manufactured refraction of natural wonders. The implications of this hyperreal augmentation are, according to Scott, that 'while beauty is enhanced, complexity is avoided. [DAK] simplifies the story of human relationships with animals, dumbing it down in true Disney fashion, instead of offering up the complexities and nuances of ecological issues. ${ }^{33}$ Critics of Avatar have said similar things. Not only does it provide a simplified relationship between Na'vi and other life forms but it also simplifies the struggles of indigenous peoples on behalf of 'the land' against modern corporate imperialism that only sees 'the land' as consumable resource. For example, Slavoj Zizek writes: 
What one should thus bear in mind is that, although Avatar's narrative is supposed to take place in one and the same 'real' reality, we are dealingat the level of the underlying symbolic economy-with two realities: the ordinary world of imperialist colonialism on the one hand, and a fantasy world, populated by aborigines who live in an incestuous link with nature, on the other. (The latter should not be confused with the miserable reality of actual exploited peoples.) The end of the film should be read as the hero fully migrating from reality into the fantasy world-as if, in The Matrix, Neo were to decide to immerse himself again fully in the matrix. ${ }^{34}$

Zizek adds that the perfected nature of Pandora signals 'it holds no place for us, the subjects who imagine it'35. Yet, we are meant to applaud the ingenuity of the film makers in creating such a fabulous and even better, more real, nature than nature itself. Again, drawing on Livingston, this 'humanisation' of nature becomes 'sanctified' for the 'advancement of the human enterprise'. ${ }^{36}$

Here the unreal nature becomes more 'real' because we like it better; and we like it better because it shows human technological prowess, which is at odds with the film's incitement towards a 'nature'-based engagement with environmental ethics.

The hyperrealism of the new and improved nature on Pandora ties back to the technologies of CGI and 3D. As Dan North reminds us:

The confusion of the real with the image is a phenomenon much criticized by Marxist ideas of visual culture, but also something for which special effects technicians claim proudly to have been aiming for many years. They might express hope that their effects will be indistinguishable from the real, but what they are actually seeking is a new, idealized simulation that is absolute representation, when the illusion is a perfect fit for the diegetic space into which it is placed. ${ }^{37}$

Special effects are supposed to 'remove the element of indexicality, the direct relationship between the image and its source'. ${ }^{38}$ As a special effects film, Avatar is certainly a success. As a representation of dark green religion, though, success is not so clear. What kind of religious or spiritual awareness or practice can be developed in a hyperreal nature? I have used the term 'refraction' to refer to Avatar's relationship to the natural world. Images are refracted when the refraction index is changed. A good example is looking at a straw in a glass of water. The refractive 
index of air is different from that of water. At the point of the change at the water surface it appears that the straw bends. This is an optical illusion. In the technological ingenuity of Avatar, nature is refracted. While we may still get a gist of the image, it is misaligned with any reality viewers may be engaging in outside the film.

Implications of this refraction can be seen in Holtmeier's discussion of PostPandoran Depression. Holtmeier, after analysing discussion on www.AvatarForums.com, observed the 'basic response of those who identified themselves as suffering from Post-Pandoran Depression has been that, after viewing Avatar, their own world seemed lackluster. ${ }^{39}$ As a result of the Pandoran world seeming more desirable-hyperreal-some fans have sought continual reimmersion in the fictional world. They are unable to 'see' their own kinship and interconnection with their own physical world. They desire the optical illusion instead.

Perhaps the problem lies, once again, with the engagement with the technological sublime. Taylor includes sublime experience of nature in his description of dark green religion. Tuck, however, reminds us that the experience of the sublime is not about 'the phenomena in-itself' and so 'has little to do with any quasi-environmentalist respect for the wonders of nature and everything to do with our experience of $i^{\prime} .^{40}$ Furthermore, Nye points out Immanuel Kant's perspective that the sublime 'does not reside in any of the things of nature, but only in our own mind, insofar as we may become conscious of our superiority over nature within, and thus also over nature without us $^{\prime} .^{41}$ Experiencing the sublime is about humans not about the natural world that triggers this experience. The experience of the sublime in a technologically constructed natural world is about feeling awe at superior human technological achievement. The fictional world of Pandora does not essentially point one to the engagement with the natural world; there is no referential index with which to engage outside the film. For those awed by the world of Pandora, a 'recursive relationship' is the only option. ${ }^{42}$ For those awed by the technology that makes the world of Pandora available for our viewing pleasure, more options of meaning are available, from simple entertainment to contemplation of the allegorical messages of the narrative. These multiple meanings could certainly lead one further into a worldview of environmental consciousness, as Holtmeier himself points out with reference to what he calls Na'vi Sympathy. However, this is 
by no means due to an inherent positioning of the film. Let us not forget, as Tuck reminds us, that science fiction special effects films 'are not concerned with being sublime, but with being profitable'.43 Richard Kahn sees this goal as the most problematic aspect of Avatar's potential for ecopedagogy. He writes:

Perhaps the worst failure of Avatar as an artifact of public pedagogy, though, is that while viscerally transcoding increasingly global fears about modern society's tendencies towards genocide, ecocide and zoocide, as with The Matrix series and other similar movies like District 9, it suggests to paying audiences that a spiritual world of social justice and biodiversity can be theirs if they will only take the first step of purchasing a movie ticket (along with whatever other necessary items from the concession stand), suspend their will to disbelieve, and so engage in the repressive desublimation of an enchanted cinematic fairy tale complete with Hollywood happy ending. ${ }^{44}$

The profit issue notwithstanding, Avatar can inspire. What it is inspiring, though, is the human ability to utilise technology to create hyperreal imagery beyond referential index, rather than any movement toward respect and/or care for the less awe-inspiring physical nature of viewers' everyday lives.

\section{-CONCLUSION}

Human representations of nature are always constructions based on previous ideological and experiential positions. My argument is not about finding a 'pure' representation of nature. I am, however, concerned with thinking through the implications of specifically technological constructions of nature such as that found in Avatar and some other forms of what Taylor calls dark green religion. The technologies of CGI and stereoscopic 3D are technologies of artifice. When we go to a movie employing these technologies we know, on some level, that what we are viewing has no reference in our real world. This is often what is so appealing about these films. When what is represented through this technology is a pristine, natural world embedding spiritual values of interconnection, I cannot help but ask what kind of spirituality is born of this construction.

Taylor and Ivakhiv see Avatar as venturing into the realm of dark green religion. This may be so. But what does a dark green religion based on a 
technologically constructed nature do in the real world? I argue that the nature of CGI and 3D technology is to create fantasy; thus, the constructed nature is 'other than' the nature we counter in our everyday lives. Furthermore, the specifics of Cameron's Pandora are not just 'other than', but 'better than' our everyday lives, and those of actual exploited indigenous peoples. Engagement with this hyperreal nature can lead down rocky paths to Post-Pandoran Depression and a dark green religion of despair: we can never have that world. This is not to say that most viewers become depressed or that no one is inspired by the allegories this narrative provides. But, the nature presented in Avatar is an optical illusion and it is only by stepping out of the technological mediation that viewers can engage with the allegories of imperial and colonial capitalism, and environmental ethics.

Chris Klassen works at the intersection of religion, environmental ethics, feminist theory, disability studies and popular culture. She is the author of Storied Selves: Shaping Identity in Feminist Witchcraft (2008), editor of Feminist Spirituality: The Next Generation (2009) and has published in Environmental Ethics, Journal of Contemporary Religion, Feminist Theology, among other academic journals. She is coeditor of the Journal of Religion and Popular Culture and teaches in the Religion and Culture department at Wilfrid Laurier University in Canada.

\footnotetext{
-NOTES

1 Bron Taylor and Adrian Ivakhiv, 'Opening Pandora's Film', The Journal for the Study of Religion, Nature and Culture, vol. 4, no. 4, 2010, p. 390.

2 Matthew Holtmeier, 'Post-Pandoran Depression or Na'vi Sympathy: Avatar, Affect, and Audience Reception', Journal for the Study of Religion, Nature and Culture, vol. 4, no. 4, 2010, p. 415.

3 Bron Taylor, Dark Green Religion: Nature Spirituality and the Planetary Future, University of California Press, Berkeley, 2010, p. 13.

${ }^{4}$ Catherine L. Albanese, Nature Religion in America: From the Algonkian Indians to the New Age, University of Chicago Press, Chicago and London, 1990.

5 On contemporary paganism, see Graham Harvey, Contemporary Paganism: Listening People, Speaking Earth, New York University Press, Washington Square, 1997; Joanne Pearson, Richard Roberts, and
} 
Geoffrey Samuel (eds), Nature Religion Today: Paganism in the Modern World, Edinburgh University Press, Edinburgh, 1998; Helen A. Berger, Evan A. Leach and Leigh S. Shaffer, Voices from the Pagan Census: A National Survey of Witches and Neo-Pagans in the United States, University of South Carolina Press, Columbia, 2003; Chris Klassen, Storied Selves: Shaping Identity in Feminist Witchcraft, Lexington Books, Lanham, MD, 2008. For feminist goddess worship, see Cynthia Eller, Living in the Lap of the Goddess: The Feminist Spirituality Movement in America, Crossroads, New York, 1993; Johanna Stuckey, Feminist Spirituality: An Introduction to Feminist Theology in Judaism, Christianity, Islam and Feminist Goddess Worship, Centre for Feminist Research, Toronto, 1998; Paul Reid-Bowen, Goddess as Nature: Towards a Philosophical Thealogy, Ashgate Publishing, London, 2007.

${ }^{6}$ See Val Plumwood, Feminism and the Mastery of Nature, Routledge, London, 1993; Catriona Sandilands, The Good-Natured Feminist: Ecofeminism and the Quest for Democracy, University of Minnesota Press, Minneapolis, 1999; Karen J. Warren, Ecofeminist Philosophy: A Western Perspective on What it is and Why it Matters, Rowmand \& Littlefield, Lanham, MD, 2000.

7 See Rayna Green, 'The Tribe Called Wannabee: Playing Indian in America and Europe', Folklore, vol. 99, no. 1, 1988, pp. 30-5; Douglas Buege, 'The Ecologically Noble Savage Revisited', Environmental Ethics, vol. 18, 1996, pp. 71-88; Sandy Marie Anglás Grande, 'Beyond the Ecologically Noble Savage: Deconstructing the White Man's Indian', Environmental Ethics, vol. 21, 1999, pp. 307-20; David Ingram, Green Screen: Environmentalism and Hollywood Cinema, University of Exeter Press, Exeter, 2000.

${ }^{8}$ Britt Istoft, 'Avatar Fandom as Nature-Religious Expression?', Journal for the Study of Religion, Nature and Culture, vol. 4, no. 4, 2010, p. 402.

9 Ibid., p. 412.

${ }^{10}$ Holtmeier, p. 415.

11 Greg Tuck, 'When More is Less: CGI, Spectacle and the Capitalist Sublime', Science Fiction Film and Television, vol. 1, no. 2, 2008, p. 252.

12 Stephen Muecke, 'Cultural Science? The Ecological Critique of Modernity and the Conceptual Habitat of the Humanities', Cultural Studies, vol. 23, no. 3, 2009, p. 413.

13 David E. Nye, The American Technological Sublime, MIT Press, Cambridge, 1994, p. 291.

14 Tuck, p. 254.

15 Tim Blackmore, 'The Speed Death of the Eye: The Ideology of Hollywood Film Special Effects', Bulletin of Science, Technology \& Society, vol. 27, no. 5, 2007, p. 368.

16 Dan North, Performing Illusions: Cinema, Special Effects and the Virtual Actor, Wallflower, London, 2008, p. 2.

17 Ibid., p. 17.

18 Dana Goodyear, 'Man of Extremes: The Return of James Cameron', New Yorker, 26 October 2009, <www.newyorker.com/reporting/2009/10/26/091026fa_fact_goodyear>.

${ }^{19}$ See Rjurik Davidson, 'Avatar: Evaluating a Film in a World of its Own', Screen Education, vol. 57, 2010, pp. 12-17. 
20 Joshua Clover, 'The Struggle for Space', Film Quarterly, vol. 63, no. 3, 2010, p. 6.

21 Ibid., p. 7.

22 Goodyear.

23 See Kirk L. Kroeker, 'Looking Beyond Stereoscopic 3D’s Revival', Communications of the ACM, vol. 53, no. 8, 2010, pp. 14-16.

24 Ibid., pp. 14-15.

25 John A. Livingston, Rogue Primate: An Exploration of Human Domestication, Key Porter Books, Toronto, 1994, p. 138.

26 Ibid., p. 142.

27 See Maria Wilhelm and Dirk Mathison, James Cameron's Avatar: An Activist Survival Guide, !t books, New York, 2009.

${ }^{28}$ Shelly R. Scott, 'Conserving, Consuming, and Improving on Nature at Disney's Animal Kingdom', Theatre Topics, vol. 17, no. 2, 2007, pp. 111-27.

${ }^{29}$ Umberto Eco, Travels in Hyperreality, trans. William Weaver, Harcourt Brace Jovanovich, New York, 1983, p. 17.

30 Ibid., p. 56.

31 Ibid., p. 44.

32 Scott, p. 114.

33 Ibid..

${ }^{34}$ Slavoj Zizek, 'Return of the Natives', New Statesman, 4 March 2010,

$<$ www.newstatesman.com/print/201003040015>.

35 Ibid.

${ }^{36}$ Livingston, p. 142.

37 North, p. 10.

38 Ibid., p. 17.

${ }^{39}$ Holtmeier, p. 416.

40 Tuck, p. 252.

${ }^{41}$ Kant quoted in Nye, p. 8.

42 Holtmeier, p. 415.

43 Tuck, p. 264.

${ }^{44}$ Richard Khan, 'Love Hurts: Ecopedagogy between Avatars and Elegies', Teacher Education Quarterly, vol. 37 , no. 4, 2010, pp. 61-2. 